\title{
TEOR DE ÁGUA DO SOLO NA EXTRAÇÃO DE FÓSFORO POR PAPEL DE FILTRO IMPREGNADO COM ÓXIDO DE FERRO
}

\author{
SOIL MOISTURE LEVEL ON PHOSPHORUS EXTRACTED \\ BY IRON OXIDE IMPREGNATED FILTER PAPER
}

\section{Gerson Luiz Miola $^{1}$ Marino José Tedesco ${ }^{2,3}$ Clesio Gianello Flávio ${ }^{2}$ Anastácio de Oliveira Camargo,}

RESUMO

O presente estudo objetivou avaliar o efeito do teor de água do solo sobre a quantidade de fósforo extraída por papéis de filtro impregnados com óxido de ferro (P,). Usaram-se seis solos do Estado do Rio Grande do Sul, previamente incubados com três doses de fósforo. A extraçâo de fósforo foi feita com $75 \%$ do teor de água retido à capacidade de campo, e em fluxo saturado. Em solo saturado, o fósforo extraído foi, em média, aproximadamente 20 vezes maior que o determinado em umidade equivalente a $75 \%$ da capacidade de campo. A extraçâo de fósforo foi linear com o tempo de contato entre o solo e o papel de filtro, no período estudado de 24 horas.

Palavras-chave: difusão de fósforo, óxido de ferro.

\section{SUMMARY}

In order to evaluate sou phosphorus extraction by iron oxide impregnated filter papers (Pi), a laboratory study was conducted with six soils from lhe Rio Grande do Sul state (Brazil) previousiy incubated with different phosphorus leveis. Phosphorus extraction was done at $75 \%$ of water retained atfield capacity and in saturated conditions. In saturated conditions, lhe soil phosphorus extracted was $m$ lhe average nearly 20 times greater than that extracted at $75 \%$ of field capacity moisture levei. Phosphorus extraction increased linearly with time during lhe 24 hours testperiod.

Key words.' phosphorus diffilsion, iron oxide.
Durante a extração de fósforo do solo por papéis de filtro impregnados com óxidos de ferro (Pi), ocorre uma remoção gradual, contínua e seletiva do fósforo em solução, com a dessorção do fósforo presente na fase sólida para manter o equilíbrio solo/solução (MENON et al., 1989a). MENON et al. (19890) afirmam que esse método de extração é pouco influenciado pelas propriedades do solo, podendo ser utilizado para solos com características físicas, químicas e mineralógicas muito variáveis. Entretanto, estudos conduzidos em solos brasileiros por REIN (1991) e BRAIDA et al. (1996) indicaram que esse método apresentou uma baixa quantidade de fósforo extraído e uma elevada variabilidade analítica dos resultados, devido, em parte, à dificuldade de ajuste do teor de água do solo. Na retirada do excesso de água das amostras pode ocorrer transporte de fósforo por fluxo de massa, além da acomodação das partículas de solo junto à superfície dos papéis, com o consequente aumento do fator tortuosidade (REIN, 1991). O estudo do teor de água do solo sobre a extração do fósforo pêlos papéis de filtro impregnados com óxidos de ferro foi, portanto, o objetivo deste trabalho.

Foram utilizados seis solos de um experimento conduzido previamente por REIN

\footnotetext{
${ }^{1}$ Engenheiro Agrônomo, Mestre, Departamento de Solos, Faculdade de Agronomia, Universidade Federal do Rio grande do Sul (UFRGS), CP 776, 90001-970, Porto Alegre - RS.

${ }^{2}$ Engenheiro Agrônomo, PhD., Professor do departamento de Solos, UFRGS. E-mail: fcamargo@vortex.ufrgs.br. Autor para correspondência.

${ }^{3}$ Bolsista do CNPq. 
(1991), cuja classificação é dada na tabela 1 (EMBRAPA/CNPS, 1999). Cada solo foi inicialmente incubado com fósforo aplicado na forma de superfosfato triplo em pó, durante quatro meses, nas quantidades indicadas na tabela 1. Após a conclusão do experimento conduzido por REIN (1991), os solos foram mantidos secos em vasos de plástico por 24 meses. Em outubro de 1993, os solos foram retirados dos vasos e homogeneizados para a avaliação em laboratório. Os valores de $\mathrm{pH}$ em água desses solos estavam próximos a 5,5 e os teores de argila variaram de 50 a $570 \mathrm{~g} \mathrm{~kg}^{-1}$ (Tabela l).
Os papéis de filtro (SS $589^{3}$ - faixa azul), com $12,5 \mathrm{~cm}$ de diâmetro, foram preparados por imersão em uma solução contendo $40 \mathrm{~g} \mathrm{~L}^{-1}$ de FeCIs. $6 \mathrm{H}_{2} \mathrm{O}$ e $20 \mathrm{~mL} \mathrm{~L}^{-1}$ de $\mathrm{HC} 1$ concentrado. Após a drenagem do excesso de solução, os papéis foram secos a $45^{\circ} \mathrm{C}$ por 5 a 6 horas, em estufa, sendo a seguir suspensos por 24 horas em dessecador contendo uma solução concentrada de $\mathrm{NH}_{4} \mathrm{OH}$. Foram, a seguir, secos a $45^{\circ} \mathrm{C}$ por 30 minutos, mantidos por algumas horas prensados para nivelar a superfície e cortados em discos de $45 \mathrm{~mm}$ de diâmetro. Maiores detalhes da metodologia de preparo dos papéis são apresentados por REIN (1991) e MIOLA (1995). A quantidade de fósforo transportado por fluxo difusivo até a superfície dos papéis foi determinada com teor de água equivalente a $75 \%$ da retida em capacidade de campo (método 075) dos solos. A extração foi feita em frascos de boca larga (com 45mm de diâmetro), sendo o disco de papel colocado entre duas porções de $10 \mathrm{~mL}$ de solo. A água foi adicionada vagarosamente pelas paredes do frasco, para reduzir o transporte do fósforo por fluxo de massa até a superfície dos papéis. Após 24 horas, os papéis foram retirados e lavados em água destilada, determinando-se o fósforo adsorvido. A quantidade de fósforo extraído pêlos papéis em fluxo saturado $\left(\mathrm{D}_{\text {sat }}\right)$ foi também determinada. Nesse trata- mento a água destilada foi adicionada até formar uma lâmina de $5 \mathrm{~mm}$ acima da superfície do solo. A colocação dos papéis, o tempo de extração e os frascos foram os mesmos que os utilizados no teste anterior. O efeito do tempo de extração na quantidade de fósforo extraído em fluxo saturado $\left(D_{\text {sat }}\right)$ foi estudado nos solos Argissolo Vermelho Distrófico latossólico e Latossolo Vermelho Distrófico típico, utilizando-se a mesma metodologia do tratamento $\mathrm{D}_{\text {sat }}$ Após a extração, os papéis foram secos a $45^{\circ} \mathrm{C}$ por 30 minutos, cortados em quatro partes, colocados em copos descartáveis de PVC $(40 \mathrm{~mL})$, adicionando-se a seguir $4 \mathrm{~mL}$ de solução de $\mathrm{H}_{2} \mathrm{SO}_{4} 2 \mathrm{~mol} \mathrm{~L} \mathrm{~L}^{-1}$. Após 6 horas, os extratos foram diluídos a $20 \mathrm{~m} \ell$, de- terminando-se o fósforo em solução por colorimetria (MURPHY \& RILEY, 1962).

${ }^{1}$ Teor de umidade à tensão de 0,1 bar (REIN, 1991).

${ }^{2}$ Determinado por hidrômetro de Bouyoucos (REIN, 1991).

${ }^{3}$ Extraído com $\mathrm{HCl} 0,05 \mathrm{~mol} \mathrm{~L}^{-1}+\mathrm{H}_{2} \mathrm{SO}_{4} 0,0125 \mathrm{~mol} \mathrm{~L}^{-1}$ (MIOLA, 1995).

${ }^{4}$ Unidades de mapeamento: PVd: Alto das Canas; SXe: Bagé; PVAd: Camaquã; PVAd; : Itapuã; LVd: Passo Fundo; LBa: Vacaria.

Ciência Rural, v. 30, n. 4, 2000. 
Pode-se observar que, em solo saturado, a extração de fósforo do solo foi, em média, de aproximadamente 20 vezes maior que no solo com $75 \%$ da capacidade de campo (Tabela 1). A maior quantidade de fósforo extraída pode ser devido ao aumento da difusão pela redução do fator tortuosidade, de acordo com a equação de difusão do P no solo, proposta por BARBER (1984). Além da simplificação da metodologia de extração, quando se satura o solo, as quantidades de fósforo extraído são maiores, reduzindo o erro experimental. Em condições de redução, entretanto, pode ocorrer aumento do $\mathrm{pH}$ do solo e solubilização de fosfates de ferro e alumínio, devido à atividade microbiana. No presente estudo, entretanto, o aumento foi menor que 0,1 unidade de $\mathrm{pH}$ em todos os solos, no período de 24 horas (MIOLA, 1995).

$\mathrm{A}$ recuperação do $\mathrm{P}$ aplicado é baixa, devido à adsorção por argila e matéria orgânica (MO), mesmo em fluxo saturado (Tabela 1), diminuindo, exponencialmente, com o aumento do teor de argila do solo (\% Recuperação = $82,62 /(12,81 \times$ teor de argila); $r=0,97))$. A menor recuperação $(0,03 \%)$ do $\mathrm{P}$ aplicado foi obtida no solo LBa, que, além de alto teor de argila, apresenta também elevado teor de MO (MIOLA, 1995). Esse fato está em desacordo com a afirmação de MENON et al. (1989b) os quais afirmam ser esse método seria pouco influenciado pelas propriedades do solo.

A adsorção de fósforo pêlos papéis de filtro impregnados com óxido de ferro em fluxo saturado, nos solos PVd e LVd, é mostrada na figura 1. Pode-se observar que a extração de $\mathrm{P}$ foi linear no período do teste ( 24 horas), podendo ser descrita por uma equação de reta passando pela origem. A capacidade de adsorção dos papéis foi, portanto, adequada para manter a concentração de fósforo próxima a zero na superfície dos mesmos e o coeficiente de difusão foi constante nesse período. Esses requisitos são essenciais para que o fósforo, adsorvido pêlos papéis de filtro impregnados com óxido de ferro, seja decorrente exclusivamente do fluxo difusivo. Maiores quantidades de fósforo poderiam ser extraídas com o aumento do tempo de extração, reduzindo assim o erro experimental. O aumento do tempo de extração, além de 24 horas, entretanto, dificulta a adoção dessa metodologia em laboratório de diagnóstico rápido da fertilidade do solo.

Os resultados permitiram concluir que a quantidade de fósforo extraído pêlos papéis de filtro impregnados com óxido de ferro aumenta com o teor de água no solo, e que a adsorção de fósforo pelos papéis de filtro impregnados com óxido de ferro é linear no período de teste de 24 horas.

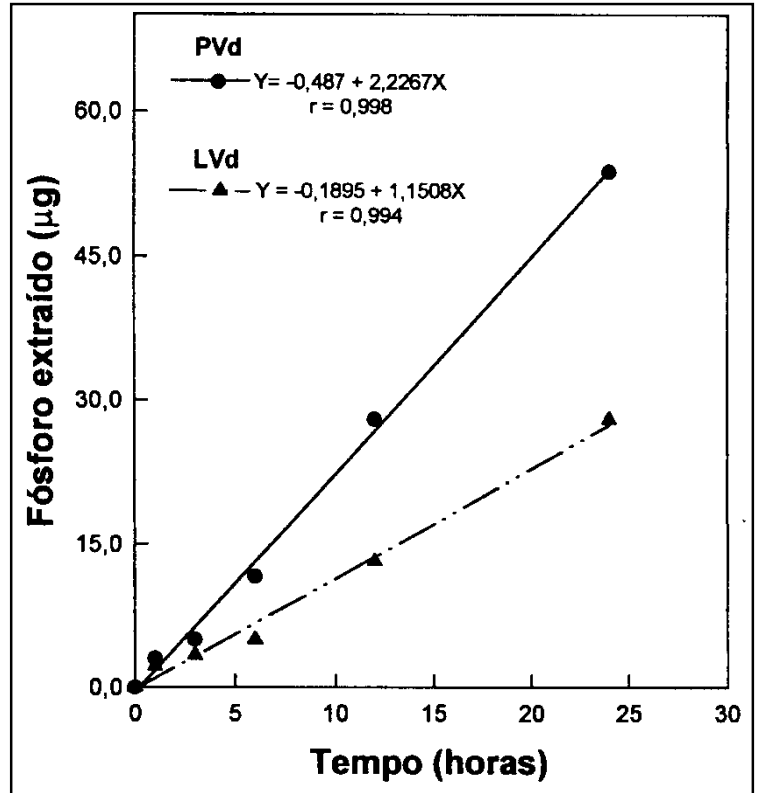

Figura 1 - Quantidades de fósforo extraído dos solos Argissolo Vermelho Distrófico latossólico (PVd) e Latossolo Vermelho Distrófico típico (LVd) por papel de filtro impregnado com óxido de ferro, em fluxo saturado.

\section{REFERENCIAS BIBLIOGRÁFICAS}

BARBER, S.A. Sou nutrient bioavailability: a mcchanistic approach. New York : John Wiley \& Sons. 1984. 398p.

BRAIDA, J.A., CAMARGO. F.A.O., ROSSO. U. et al. Comparação de métodos de determinação da disponibilidade de fósforo do solo para as plantas. Revista Brasileira de Ciência do Solo, Campinas, v.20, n.2, p.345-347,1996.

EMBRAPA/CNPS. Sistema brasileiro de classificação de solos. Brasília : SPI-EMBRAPA, 1999. 412p.

MENON, R.G., CHIEN, S.H., HAMMOND, L.L. The Pi soil phosphorus test: a new approach to testing for soil phosphorus. Muscle Shoois, Alabama : Intemational Fertilizer Development Centre, 1989a. 1Op.

MENON, R.G., CHIEN, S.H., HAMMOND, L.L. et al. Modified techniques for preparing paper strip for the new P; soil test for phosphorus. Fertilizer Research, Dordrescht, v.19, n.1, p.85$91,1989 b$.

MIOLA, G.R. Extração de P, K, Ca e Mg do solo por diferentes métodos e avaliação da disponibilidade de $\mathbf{P}$ para as plantas. Porto Alegre, 1995. 130p. Dissertação (Mestrado em Agronomia) - Programa de Pós-graduaçâo em Agronomia, Universidade Federal do Rio Grande do Sul, 1995.

MURPHY, J., RILEY, J.P. A modified singie method for determination of phosphates in natural waters. Analytica Chimica Acta, Amsterdan, v.27, n.1, p.31-36, 1962.

REIN, T. A. Estimativa de fluxo difusivo de fósforo nos solos e avaliação de sua disponibilidade às plantas. Porto Alegre, 1991. 131 p. Tese (Mestrado em Agronomia) - Programa de Pós-graduação em Agronomia, Universidade Federal do Rio Grande do Sul. 